\section{Estehan Pikiewicz}

Médico especialista en Psiquiatría, AP miembro de la Escuela de la Orientación Lacaniana (EOL), Asociación Mundial de Psicoanálisis (AMP) y Centro Descartes, miembro de APSA, ex jefe de Servicio de Salud Mental del Hospital Zonal de Esquel

Resumen: El texto ubica el término justicia en su etimología y acepción general. Desde su origen y relación con la religión, pasando por la historia, la política y la ciencia del derecho sintéticamente. Y cómo, en la realidad actual, resalta la querella de la justicia a través de términos como lawfare y otras tendencias de época. Destacando finalmente que se trata a nivel de la estructura de una "injusticia" irreductible, que el psicoanálisis conceptualiza como significante del Otro tachado.

Palabras clave: Justicia - Ley - Lazo - Violencia - Injusticia

\section{GENERALIDADES}

En su etimología, el término justicia deriva del latín en tanto que derecho, significa lo que se ajusta, entre otras definiciones. El diccionario expresa que es el principio moral que inclina a obrar y juzgar respetando la verdad y dando a cada uno lo que corresponde. Diríase distribución de costos y beneficios entre los integrantes de una comunidad, conforme a un criterio o escala de criterios. A qué criterio o criterios se ajusta dicha distribución, es lo que hace variar la acepción de la palabra. No obstante, dado que la jerarquía de los criterios o escala de criterios supuestos para dicha distribución, suelen referirse a valores morales sedimentados culturalmente, la justicia se relaciona así, a la dignidad humana, el bien común, la ley. De allí que el término sea en sí referencial como fundamento cultural. Se deduce que, además, se vincula a la necesidad de mantener la armonía entre los integrantes de una comunidad. Igualmente, desde otro ángulo, y sin el afán de una exégesis teológica ni mucho me-
Abstract: The text locates the term justice in its etymology and general meaning. From its origin and relationship with religion, through history, politics and law science synthetically. And how, in the current reality, highlights the complaint of justice through terms such as lawfare and other trends of the time. Finally stressing that it is at the level of the structure of an irreducible "injustice" that psychoanalysis conceptualizes as a signifier of the crossed out Other.

Key words: Justice - Llaw - Bond - Violence - Injustice

nos, sabemos que hay en la Santa Biblia suficiente cantidad de versículos respecto de la justicia. $\mathrm{O}$ como en la Roma Antigua, que entendían que el derecho y la justicia eran un regalo de la divinidad. Diríase grosso modo así, que justicia es una cualidad, atributo de la divinidad; y que según la tradición judeo-cristiana, supone aquello que se expresa como alianza inaugural: el pacto entre Dios y los hombres en el monte Sinaí. Dios Padre fuente de toda razón y justicia, guía y salvaguarda de su pueblo a cambio de fidelidad, conformidad, sinceridad y amor con él, a través de las tablas de la ley. Se establece de este modo lo que es un orden. Lo que forma parte de la organización del lazo entre los hombres en tanto que leyes, un sistema de normas a observar y/o aplicar.

Sobre este último renglón, la filosofía política de Roberto Espósito, resalta algo significativo. Porque si bien se trata de un orden, ese elemento significativo es clave y hace al previo a toda comunidad (Espósito la llama comunidad originaria, caótica, ilimitada). Va a decir que el punto en 
que se funda la organización de los lazos entre los hombres, es un acto violento. Afirma que "...la comunidad misma se muestra fundada por una violencia homicida (...) entre hermanos (...) Por fuera del logos, del discurso, tanto como del nomos, de la ley, esa comunidad, exactamente antinómica, constituye una amenaza insostenible para todos sus integrantes."(1) Este planteo (si bien en otra disciplina) es congruente con aquello que Freud, como origen mítico de la ley, desarrolla sobre la muerte-asesinato del Padre primordial y del incesto (Tótem y Tabú) - retomaremos este aspecto de lo violento.

Siguiendo entonces con Freud, ello es lo que funda el orden del lazo entre hermanos. Horda primordial dirá, donde “...el totemismo supone un primer modo de organización social y por lo tanto posee un sistema de normas que se aplican tanto a una comunidad, a un conjunto de individuos, como a un hombre."(2) Diríase que, en tanto acontecimiento excepcional de hecho, pasa a un estatuto de ficción discursiva, el del derecho; eso que el jurista romano de origen fariseo, Ulpiano, designara como constante y perpetua voluntad de dar a cada uno su derecho, obrar siempre conforme a derecho en las acciones humanas.

\section{JUSTICIA ... ¿QUE JUSTICIA?}

A grandes rasgos, se demarca así, lo que se conoce respecto de la justicia como su fundamento cultural/subjetivo (el consenso general acerca de lo bueno y lo malo, idea de virtud, principio moral/ético, etc.) y el fundamento formal/jurídico (la codificación en disposiciones escritas, aplicadas por personas especialmente designadas, etc.). Ahora, y más acá de lo divino, si justicia entonces es eso pedido, demandado, en las vías de dar a cada uno su derecho, aquello que a través del sistema de normas mantendría la armonía de una comunidad frente a los conflictos en el seno de ella, etc., resulta que diríase hay pluralidad: justicias. Existen según las épocas, teorías y definiciones diversas sobre la justicia y su derivada e implicancia en el campo del derecho y por lo tanto de la política. Platónica como armonía social, Aristotélica como igualdad proporcional; la de Tomás de Aquino como ley natural dada por Dios (derecho que luego derivó en los derechos humanos); la utilitarista, o la que toma en cuenta los bienes producidos y la riqueza de la que el humano dispone, planteándose así la justicia dis- tributiva, etc. Y no solo su pluralidad, sino acaso, lo que en el siglo XXI nos atrevemos a nombrar como la querella sintomática de la justicia. Esto es la desconfianza generalizada del sistema jurídico, o la solución de compromiso denominada Servicio de Atención a la víctima de delito (rama de la criminología que asiste a los damnificados en nombre del paradigma moderno del trauma generalizado), la queja por su "lentitud" o burocrática en el proceso para su obtención (rasgo argentino), los casos de justicia por mano propia; o las intersecciones con la ciencia neuro que hacen que se hable de neurolaw, o el término de referencia actual en el ámbito jurídico, conocido como lawfare (término de origen británico que es la contracción de las palabras law (ley) y warfare (guerra) como alusión a una crisis en dicho ámbito. También escuetamente, por ejemplo, como eco de la política criminal actual según la sensibilidad social, y los pedidos iterativos de la población, de castigos ejemplares ante hechos delictivos de impacto público, y otros tantos etcéteras en este nivel.

Por ello y retomando los desarrollos freudianos, pareciera que más bien de lo que se trata, es que a nivel de la justicia prevalece y predomina, al interior, su propio irreductible: la injusticia. Diríamos es su marca de origen. ¿A qué nos referimos? Como señala Gustavo Dessal, “...el mito del parricidio es una metáfora, cuya función es la de mostrar la lógica sobre la que se construye el mecanismo de la cultura y el lazo social. El padre originario, exceptuado de la ley, es quien funda la prohibición, basada en el comienzo sobre la más absoluta arbitrariedad". (3) Justamente acentuando el final de esta frase, encontramos el mismo eco en Carl Schmitt (autor que encarna en el derecho, la rama llamada decisionismo en oposición al formalismo jurídico de Kelsen); lo que este filósofo jurista concibiera en el campo jurídico, con la idea que la excepción funda el todo. Es decir, hay siempre alguien que decide, en tanto que excepción y... arbitrariamente! La injusticia es ese punto de arbitrariedad. Lugar vacío, donde convergen deseo y goce, en tanto que pasiones e intereses, como poder, prestigio, posesión, etc. de aquel que juzga. Cuestión que en la actualidad el sentido común intuye como lo que acontece detrás del escenario jurídico. Jacques Lacan lo decía con su estilo hace aproximadamente setenta años: “...el grupo que hace la ley no está, por razones, 
sociales completamente seguro respecto de la justicia de los fundamentos de su poder..." (4) Planteado desde otra perspectiva, ¿no es esa arbitrariedad, la que puede en esta dirección, leerse en el libro de Job respecto de Dios?; ¿sus caprichos, su ferocidad, su injusticia radical?

Además, si la marca de origen es el acto violento, la crueldad, la destrucción, la venganza, como tendencias humanas, son ese punto éxtimo de la justicia donde todo el desarrollo de la ciencia del derecho hasta nuestros días, bien puede anotarse como formación reactiva. Como cita Roberto Espósito de Walter Benjamín respecto del funcionamiento del derecho: "Al comienzo siempre un acto violento (...) funda el orden jurídico. (...) el derecho tiende a excluir cualquier otra violencia externa a sus procedimientos. Pero sólo puede hacerlo violentamente, recurriendo a esa misma violencia que condena. (...) el derecho no es otra cosa que violencia a la violencia para el control de la violencia." (5)

\section{DERECHO A LA INJUSTICIA}

Si bien sabemos que el filosofo Enrique Marí, ha difundido entre nosotros los trabajos de Pierre Legendre sobre derecho, religión, habiendo incorporado en sus consideraciones la teoría del inconsciente en el campo jurídico (cuestiones muy bien expuestas e investigadas por la psicoanalista Graciela Musachi) (6), resta por constatar consecuencias efectivas en ese campo predominantemente positivista. Lo mismo podría decirse al respecto, por la vía “...de la red política lacaniana mundial, como experiencia analítica y de Escuela en sus consecuencias políticas llevadas al grupo social..." (7) conocida como ZADIG, establecida recientemente por Jacques-Alain Miller.
Mientras tanto, diríase que la experiencia analítica se inicia con una demanda que tiene por substrato, la injusticia. Efectivamente, el analizante enuncia una queja que podría resumirse en que le ha sido sustraído la base existencial que le falta. Y en ese dolor de existir, como resalta Gustavo Dessal a través del libro de Job, resuena la pregunta (a Dios, al Otro) “¿Qué quieres de mí?” (8) Freud denominó esa condición como Hilflosigkeit, elucubrado por Lacan como sujeto tachado en tanto significante del Otro barrado. Por ello la dirección en la experiencia analítica, es ir derecho a esa injusticia por la vía del síntoma. Y hacer responder por esa injusticia irreductible e incurable, con lo que mejor se ajuste sinthomaticamente a ese vacío, para cada uno.

\section{Notas}

(1)Espósito, Roberto: “Comunidad y violencia", en Diez pensamientos acerca de la política, Ed. Fondo de Cultura Económica, Bs. As., 2012, pág. 273/278.

(2)Fasano, Cecilia: “A la luz del psicoanálisis la ley es otra cosa”, en Revista Descartes Nro. 26, Ed. Otium Ediciones, Bs. As., noviembre 2017, pág. 189.

(3)Dessal Gustavo/Zygmunt Bauman: "Comentario a Buscar en la moderna Atenas una respuesta a la antigua Jerusalem”, en El retorno del péndulo - sobre psicoanálisis y el futuro del mundo líquido, Ed. Fondo de Cultura Económica, Bs. As., 2014, pág. 132.

(4)Lacan Jacques: "Introducción teórica a las funciones del psicoanálisis en criminología” cap. 4, en Escritos 1, Ed. Siglo XXI Editores, Bs. As., 1988, pág. 129.
(5)Esposito, Roberto: “Comunidad y violencia”, en Diez pensamientos acerca de la política, Ed. Fondo de Cultura Económica, Bs. As., 2012, pág. $281 / 282$.

(6)Musachi, Graciela: “Ficciones”, en Fantasmas colectivos - clínica del sujeto, Ed. UNSAM, prov. de Bs. As., 2015, pág. 75/76.

(7)Bassols, Miquel: “Campo Freudiano, Año Cero" en la ELP, Elecciones analíticas en Lacan Quotidien Nro. 758, sitio web EOL, domingo 21 de enero de 2018.

(8)Dessal Gustavo/Zygmunt Bauman: "Comentario a Buscar en la moderna Atenas una respuesta a la antigua Jerusalem”, en El retorno del péndulo - sobre psicoanálisis y el futuro del mundo líquido, Ed. Fondo de Cultura Económica, Bs. As., 2014, pág. 131/132. 